Article

\title{
The Constituents of Michelia compressa var. formosana and Their Bioactivities
}

\section{Yu-Yi Chan ${ }^{1, *}$, Shin-Hun Juang ${ }^{2}$, Guan-Jhong Huang ${ }^{3}$, Yu-Ren Liao ${ }^{4}$, Yu-Fon Chen ${ }^{5}$, Chia-Che Wu ${ }^{6}$, Hui-Ting Chang ${ }^{6}$ and Tian-Shung Wu ${ }^{4, *}$}

1 Department of Biotechnology, Southern Taiwan University of Science and Technology, Tainan 71005, Taiwan

2 Graduate Institute of Pharmaceutical Chemistry, China Medical University, Taichung 40402, Taiwan; E-Mail: paul@mail.cmu.edu.tw

3 Department of Pharmacy, China Medical University, Taichung 40402, Taiwan; E-Mail: gjhuang@mail.cmu.edu.tw

4 Department of Chemistry, National Cheng Kung University, Tainan 70101, Taiwan; E-Mail: truthloveroy@yahoo.com.tw

5 Department of Life Sciences, National Cheng Kung University, Tainan 70101, Taiwan; E-Mail: yufons@gmail.com

6 School of Forestry and Resource Conservation, National Taiwan University, Taipei 10617, Taiwan; E-Mails: ujin1205@gmail.com (C.-C.W.); chtchang@ntu.edu.tw (H.-T.C.)

* Authors to whom correspondence should be addressed;

E-Mails: tswu@mail.ncku.edu.tw (T.-S.W.); yuyichan@mail.stust.edu.tw (Y.-Y.C.); Tel.: +886-627-575-75 (ext. 65333) (T.-S.W.); +886-625-331-31 (ext. 6921) (Y.-Y.C.); Fax: +886-627-405-52 (T.-S.W.); +886-624-257-41 (Y.-Y.C.).

Received: 2 April 2014; in revised form: 8 May 2014 / Accepted: 19 May 2014 /

Published: 17 June 2014

\begin{abstract}
Phytochemical investigation of the heartwood of Michelia compressa afforded forty-four compounds, which were identified by comparison of experimental and literature analytical and spectroscopic data. Some compounds were evaluated for their anti-inflammatory and anticancer bioactivities. The result showed that roemerine (1) and cyathisterol (2) exhibited significant nitric oxide (NO) inhibition, with $\mathrm{IC}_{50}$ values of $8.5 \pm 0.3$ and $9.6 \pm 0.5 \mu \mathrm{g} / \mathrm{mL}$, respectively. In addition, liriodenine (3) and oliveroline (4) exhibited cytotoxicity to human nasopharyngeal carcinoma (NPC-TW01), non-small cell lung carcinoma (NCI-H226), T cell leukemia (Jurkat), renal carcinoma (A498), lung carcinoma (A549) and fibrosarcoma (HT1080) cell lines with IC $_{50}$ values in the range of 15.7-3.68 $\mu \mathrm{M}$.
\end{abstract}


Keywords: Michelia formosana; Magnoliaceae; NO inhibition; macrophage; cytotoxicity

\section{Introduction}

Michelia (Magnoliaceae) consists of about 30 species, living in subtropical and tropical Asia, from eastern India through the Indo-Chinese Peninsula to Southern China, Southern Japan and southward to Malay Islands. One species is native to Taiwan [1]. Michelia species have been used in the treatment of cancer by indigenous peoples. Such as, Michelia champaca has been used in India for the treatment of abdominal tumors as well as Michelia hypoleuca and Michelia officinalis for carcinomatous sores and leukemia respectively, in China. Experimentally, Michelia grandiflora, Michelia compressa and Michelia kobus have proven anticancer activity in various tumor systems [2]. In addition, the extract of Michelia champaca leaves has also exhibited an anti-inflammatory activity in pro-inflammatory conditions [3]. Moreover, the aporphine alkaloid and sesquiterpene lactone constituents of this genus have caused a great interest due to their diverse structures and significant biological activities [2-6].

Michelia compressa var. formosana is an evergreen tree mainly distributed in Taiwan, Japan, and Ryukyu Islands [1]. In the previous literature, its heartwood exhibited high resistance against rots due to the presence of liriodenine [6]. The chemical investigations of leaves [5,7], barks [8], root barks [2], root wood [4], heartwood [9,10], stems [11], and pericarps [12] have been reported, but the anti-inflammatory and cytotoxic properties of constituents from heartwood are not known.

In our future research, we focus on the identification of anticancer and anti-inflammatory drug leads from natural sources. In our research, the bioactive constituents of the heartwood of $M$. compressa were searched for by assaying the effects on nitric oxide (NO) inhibition in LPS (lipopolysaccharide)-activated mouse peritoneal macrophages and evaluating their cytotoxicity of six human cancer cell lines including human nasopharyngeal carcinoma (NPC-TW01), non-small cell lung carcinoma (NCI-H226), T cell leukemia (Jurkat), renal carcinoma (A498), lung carcinoma (A549) and fibrosarcoma (HT1080) cell lines.

\section{Results and Discussion}

\subsection{Isolation and Characterization of Compounds}

Air-dried and powdered heartwood of M. compressa var. formosana was soaked with ethanol at room temperature, and the combined extracts were concentrated to give a deep brown syrup. The crude extract was suspended into water and partitioned with $\mathrm{CHCl}_{3}$ to afford $\mathrm{CHCl}_{3}$ layer and water solubles, respectively. Purification of the $\mathrm{CHCl}_{3}$ soluble fraction by column chromatography yielded roemerine $(\mathbf{1}, 13.7 \mathrm{mg})$ [13], cyathisterol $(2,10.8 \mathrm{mg})$ [14], liriodenine (3, 379 mg) [10], oliveroline (4, $2.1 \mathrm{mg})$ [15], ushisurine (5, $230 \mathrm{mg})$ [10], dihydrocostunolide (6,3.6 mg) [16], (-)- $N$-formylanonaline (7, $7.9 \mathrm{mg})$ [15], $6 \alpha$-hydroxy- $\beta$-sitostenone $(\mathbf{8}, 4.7 \mathrm{mg})$ [15], ferulic acid $(\mathbf{9}, 5.9 \mathrm{mg})$ [17], $\beta$-sitosterone (10, $10.3 \mathrm{mg})$ [18], $\beta$-stigmastenone (11, $11.5 \mathrm{mg})$ [18], costunolide (12, $1.2 \mathrm{mg}$ ) [19], $\beta$-sitostanone (13, $1.6 \mathrm{mg})$ [18], dehydroroemerine (14, $1.9 \mathrm{mg})$ [20], ferruginol (15, $1.2 \mathrm{mg})$ [21], sugiol (16, $1.3 \mathrm{mg})$ [22],

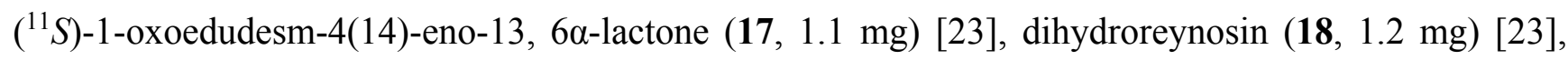
romucosine $(\mathbf{1 9}, 1.6 \mathrm{mg})$ [24], 11,13-dihydrosantamarin $(\mathbf{2 0}, 0.8 \mathrm{mg})$ [25], 2-methylanthraquinone 
(21, $1.5 \mathrm{mg})$ [26], methyl 22-feruloyloxydocosanoate (22, $1.9 \mathrm{mg})$ [27], annonbraine (23, $1.1 \mathrm{mg})$ [28], ferulic aldehyde (24, $0.7 \mathrm{mg})$ [29], secoroemerine (25, $0.6 \mathrm{mg})$ [30], blumenol A (26, $1.3 \mathrm{mg})$ [31],

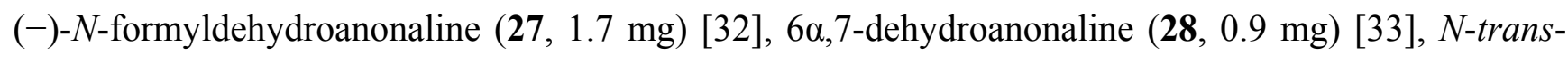
feruloyltyramine $(\mathbf{2 9}, 1.0 \mathrm{mg})$ [27], $N$-trans-feruloylmethoxytyramine (30, $1.1 \mathrm{mg})$ [17], syringaresinol $(\mathbf{3 1}, 1.7 \mathrm{mg})$ [34], cepharadione-A (32, $0.9 \mathrm{mg})$ [35], aristolic acid II (33, $0.8 \mathrm{mg})$ [17], $O$-acetyl-ushinsunin (34, $0.9 \mathrm{mg})$ [10], (+)-isolaricirensinol (35, $1.6 \mathrm{mg})$ [34], northalifoline (36, $1.5 \mathrm{mg})$ [35], cassyformin (37, $2.0 \mathrm{mg})$ [36], 3-[2-(4-hydroxy-3-methoxyphenyl)-3-hydroxymethyl-7-methoxy-2,3dihydro-1-benzofuran-5-yl]propan-1-ol (38, $1.7 \mathrm{mg})$ [37], dehydrodiconiferyl alcohol (39, $0.8 \mathrm{mg})$ [38], divanillyl tetrahydrofuran (40,1.9 $\mathrm{mg}$ ) [39], methyl vanillate (41, $0.7 \mathrm{mg})$ [24], noroliveroline $(42,0.7 \mathrm{mg})$ [40], 1-acetyl- $\beta$-carboline $(43,1.6 \mathrm{mg})$ [41] and trans-feruloyloxyhexacosanoic acid (44, $2.3 \mathrm{mg})$ [42], and their structures were identified by comparison of their physical and spectroscopic data with those reported in the literature.

\subsection{Inhibitory Effects of Isolated Compounds on Nitric Oxide (NO) Production}

The isolated compounds $(\mathbf{1}-\mathbf{3}, \mathbf{5}, \mathbf{7}, \mathbf{9}-\mathbf{1 1})$ were subjected into the examination of their effects on LPS-induced NO production in murine RAW 264.7 macrophage cell line. RAW 264.7 cells were incubated with various concentrations of these compounds and LPS $(100 \mathrm{ng} / \mathrm{mL})$ for $24 \mathrm{~h}$ for detection of NO production. NO plays a role as neurotransmitter, vasodilator, and immune regulator in a variety of tissues at physiological concentration. High levels of NO produced by inducible nitric oxide synthase (iNOS) have been defined as a cytotoxic molecule in inflammatory process [43]. After $24 \mathrm{~h}$ incubation, the culture medium of non-LPS treated macrophages was used as background levels of nitrite. Nitrite accumulated in the culture medium was estimated by the Griess reaction as an index for NO release from the cells. In the present study, NO production was significantly decreased by the treatment with roemerine (1) and cyathisterol (2) (Figure 1) in a dose-dependent manner, with IC50 values of $8.5 \pm 0.3$ and $9.6 \pm 0.5 \mu \mathrm{g} / \mathrm{mL}$, respectively (Table 1 ).

Figure 1. Structure of compounds 1-4.

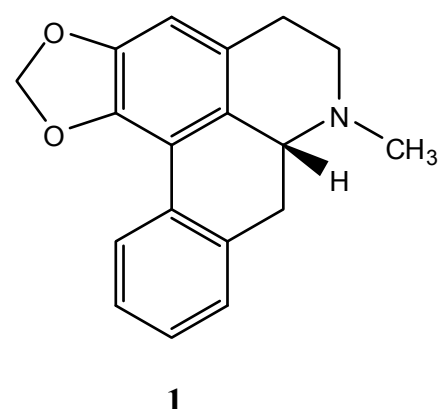<smiles>O=C1c2ccccc2-c2c3c(cc4ccnc1c24)OCO3</smiles><smiles>CN1CCc2cc3c(c4c2[C@@H]1[C@H](O)c1ccccc1-4)OCO3</smiles>

3

4

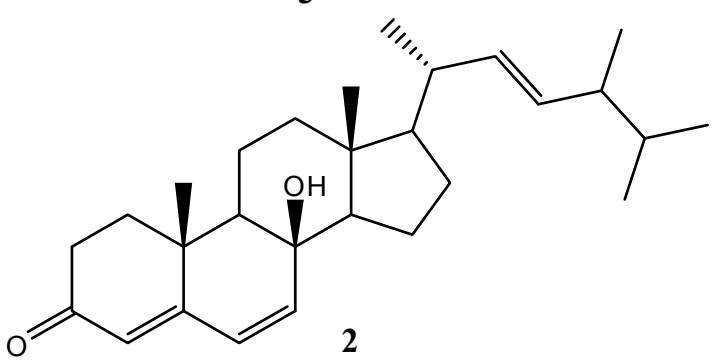


Table 1. Inhibitory effects of compounds $\mathbf{1}$ and $\mathbf{2}$ from the leaves of Michelia compressa var. formosana on LPS-induced Nitric Oxide (NO) production in RAW 264.7 cells.

\begin{tabular}{ccccc}
\hline Compound & Dose $(\mathbf{1 0 0} \mathbf{~ n g} / \mathbf{m L})$ & Cell Viability (\% of Control) & NO Level & IC $_{\mathbf{5 0}}(\boldsymbol{\mu g} \mathbf{g} \mathbf{m L})$ \\
\hline control & $(-)$ & $94.5 \pm 2.8$ & $0.7 \pm 0.4$ & - \\
\hline LPS & $(+)$ & $101.7 \pm 0.5$ & $19.7 \pm 0.2^{\# \# \#}$ & - \\
\hline \multirow{2}{*}{$\mathbf{1}$} & 1.25 & $97.7 \pm 5.1$ & $19.1 \pm 1.0$ & \\
& 2.5 & $94.7 \pm 2.9$ & $18.3 \pm 0.5$ & \\
& 5 & $89.8 \pm 4.8$ & $12.3 \pm 0.2 * *$ & $8.5 \pm 0.3$ \\
& 10 & $86.9 \pm 2.7$ & $9.1 \pm 0.1 * * *$ & \\
\multirow{2}{*}{$\mathbf{2}$} & 1.25 & $81.3 \pm 1.7$ & $6.5 \pm 0.3 * * *$ & \\
& 2.5 & $85.3 \pm 1.9$ & $20.6 \pm 0.1$ & \\
& 5 & $84.3 \pm 2.5$ & $20.0 \pm 0.5$ & \\
& 10 & $82.7 \pm 1.7$ & $17.0 \pm 0.8 *$ & $9.6 \pm 0.5$ \\
& 20 & $80.6 \pm 5.4$ & $9.4 \pm 0.7 * * *$ & \\
\hline
\end{tabular}

The data were presented as mean \pm S.D; ${ }^{\# \#, ~ c o m p a r e d ~ w i t h ~ s a m p l e ~ o f ~ c o n t r o l ~ g r o u p ; ~}{ }^{*}, p<0.05,{ }^{* *}, p<0.01$, and $* * *, p<0.001$ were compared with LPS-alone group; - , not detectable; $(-)$, no LPS adds to RAW 264.7 cells; (+), LPS adds to RAW 264.7 cells.

\subsection{Anticancer Bioactivities of Isolated Compounds}

To assess the growth inhibitory activity of the isolated compounds 1-11 toward cancer cells, six different cell lines from malignant tumors including human nasopharyngeal carcinoma (NPC-TW01), non-small cell lung carcinoma (NCI-H226), T cell leukemia (Jurkat), renal carcinoma (A498), lung carcinoma (A549) and fibrosarcoma (HT1080) cell lines were used. The result showed that liriodenine (3) and oliveroline (4) (Figure 1) treatment exhibited inhibition of human cancer cell lines with $\mathrm{IC}_{50}$ values in the range of 15.7-3.68 $\mu \mathrm{M}$ (Table 2). Moreover, liriodenine (3) and oliveroline (4) exhibited the powerful inhibitory activity against renal carcinoma (A498) with $\mathrm{IC}_{50}$ valuses 4.52 and $3.68 \mu \mathrm{M}$, respectively. Our study suggests the heartwood of $M$. compressa var. formosana and its isolates could be viewed as potential candidates for the development of anti-cancer drugs.

Table 2. Cytotoxicity of compounds 3 and 4.

\begin{tabular}{ccccccc}
\hline \multirow{2}{*}{ Compounds } & TW01 Lines & H226 & Jurkat & A498 & A549 & HT1080 \\
\cline { 2 - 7 } & $\mathbf{I C}_{\mathbf{5 0}}(\boldsymbol{\mu M})$ & $\mathbf{I C}_{\mathbf{5 0}}(\boldsymbol{\mu M})$ & $\mathbf{I C}_{\mathbf{5 0}}(\boldsymbol{\mu M})$ & $\mathbf{I C}_{\mathbf{5 0}}(\boldsymbol{\mu M})$ & $\mathbf{I C}_{\mathbf{5 0}}(\boldsymbol{\mu M})$ & $\mathbf{I C}_{\mathbf{5 0}}(\boldsymbol{\mu M})$ \\
\hline $\mathbf{3}$ & 8.99 & 14.71 & 15.7 & 4.52 & 8.82 & 9.75 \\
$\mathbf{4}$ & 5.88 & 12.28 & 13.28 & 3.68 & 5.50 & 6.93 \\
\hline
\end{tabular}

\section{Experimental Section}

\subsection{General Procedures}

UV spectra were obtained with a Hitachi UV-3210 spectrophotometer (Hitachi, Tokyo, Japan), and IR spectra were recorded on a Shimadzu Fourier transform infrared spectroscopy (FT-IR) DR-8011 spectrophotometer spectrophotometer (Olympus, Tokyo, Japan). Optical rotations were measured with a JASCO P-2000 digital polarimeter in a $0.5 \mathrm{dm}$ cell. The electrospray ionization mass spectrometry 
(ESI-MS, Bruker, Bremen, Germany) and high resolution electrospray ionization mass spectroscopy (HRESI-MS, Bruker, Bremen, Germany) were taken on a Bruker Daltonics APEX II 30e spectrometer (Bruker, Bremen, Germany). The ${ }^{1} \mathrm{H}$ and ${ }^{13} \mathrm{C}$ nuclear magnetic resonance spectroscopy $\left({ }^{1} \mathrm{H}\right.$ and $\left.{ }^{13} \mathrm{C} \mathrm{NMR}\right)$ spectra were measured using Bruker Avance-300 (Bruker Biospin Inc., Ettlingen, Germany), AMX-400 (Bruker Biospin Inc., Ettlingen, Germany), and AV-500 spectrometers (Bruker Biospin Inc., Ettlingen, Germany) with tetramethylsilane (TMS) as the internal reference, and chemical shifts are expressed in $\delta$ (ppm). Silica gel (70-230 and 230-400 mesh; Merck KGaA, Darmstadt, Germany) and Spherical C18 reversed phase silica gel (RP-18; particle size 20-40 $\mu$; Silicycle, Quebec City, QC, Canada) were used for column chromatography (CC), and silica gel 60 F254 (Merck, Darmstadt, Germany) and RP-18 F254S (Merck) were used for thin layer chromatography (TLC) and preparative TLC, respectively.

\subsection{Plant Materials}

The heartwood of M. compressa var. formosana (Magnoliaceae) was collected from Taipei Hsien, Taiwan, in June 2012 and verified by Prof. Kuoh, C.-S. A voucher specimen (TSWu-2012006) has been deposited in the Herbarium of National Cheng Kung University, Tainan, Taiwan.

\subsection{Extraction and Isolation}

The heartwood of M. compressa var. formosana $(10 \mathrm{~kg})$ was air-dried and powdered and soaked $(24 \mathrm{~h})$ three times with $20 \mathrm{~L}$ ethanol at room temperature, and the combined extracts were concentrated under reduced pressure to give deep brown syrup (720 g). The crude extract was suspended into water $(1 \mathrm{~L})$ and partitioned five times with $1 \mathrm{~L} \mathrm{CHCl}_{3}$ to afford $\mathrm{CHCl}_{3}$ layer $(245 \mathrm{~g})$ and water solubles $(462 \mathrm{~g})$, respectively, after removal of the corresponding solvent.

The $\mathrm{CHCl}_{3}$ soluble extracts were purified by silica gel column chromatography eluted with $\mathrm{CHCl}_{3}$ and $\mathrm{MeOH}$ gradients to afford 7 fractions. Fraction 2 was subjected to silica gel column chromatography eluted with $n$-hexane/acetone (25:1) to yield 2, 5, 6, 10-21, and 43. Purification of fraction 4 by column chromatography with silica gel was eluted by step gradients of $n$-hexane/acetone (15:1 and 9:1) to afford 7 and 22-24. Fraction 5 was subjected to silica gel column chromatography eluted with $n$-hexane/acetone $(15: 1)$ to yield $\mathbf{3}, \mathbf{8}, \mathbf{2 5}-\mathbf{3 3}$, and $\mathbf{4 4}$. Separation of fraction 7 by column chromatography with silica gel eluted by $n$-hexane/acetone (7:1) yielded $\mathbf{1 , 4 , 9}$, and 34-42.

\subsection{Determination of Inhibitory Effects on NO Production}

\subsubsection{Chemicals}

LPS (endotoxin from Escherichia coli, serotype 0127:B8), MTT (3-[4,5-dimethylthiazol-2-yl]-2, 5-diphenyltetrazolium bromide) and other chemicals were purchased from Sigma Chemical Co. (St. Louis, MO, USA).

\subsubsection{Cell Culture}

A murine macrophage cell line RAW 264.7 (Bioresources Collection and Research Center, BCRC No. 60001) was purchased from the BCRC of the Food Industry Research and Development Institute 
(Hsinchu, Taiwan). Cells were cultured in plastic dishes containing Dulbecco's Modified Eagle Medium (DMEM, Sigma, St. Louis, MO, USA) supplemented with 10\% fetal bovine serum (FBS, Sigma) at $37{ }^{\circ} \mathrm{C}$ in $5 \% \mathrm{CO}_{2}$ /air and subcultured every 3 days at a dilution of $1: 5$ using $0.05 \%$ trypsin- $-0.02 \%$ EDTA in $\mathrm{Ca}^{2+}$ - and $\mathrm{Mg}^{2+}$-free Dulbecco's phosphate-buffered saline (DPBS).

\subsubsection{Cell Viability Assay}

Cells were cultured in 96-well plates at a density of $2 \times 10^{5}$ cells/well in 10\% FBS DMEM medium and treated with compounds $(\mathbf{1}-\mathbf{3}, \mathbf{5}, \mathbf{7}, \mathbf{9}-\mathbf{1 1})$ in the presence of LPS (100 ng/mL) for $24 \mathrm{~h}$. Cells were washed twice with DPBS and incubated with MTT $(100 \mu \mathrm{L}, 0.5 \mathrm{mg} / \mathrm{mL})$ for $2 \mathrm{~h}$ to analyze cell viability. The medium was discarded and dimethyl sulfoxide (DMSO) $(100 \mu \mathrm{L})$ was added. After $0.5 \mathrm{~h}$ incubation, absorbance at $570 \mathrm{~nm}$ was read using a microplate reader (Molecular Devices, Orleans Drive, Sunnyvale, CA, USA).

\subsubsection{Measurement of Nitric Oxide/Nitrite}

The presence of nitrite (a metabolite of NO) in the culture medium was analyzed with the Griess assay (Sigma-Aldrich) as described previously [44]. Briefly, cells cultured in 96-well plates were treated with compounds in the presence of LPS $(100 \mathrm{ng} / \mathrm{mL})$ at $37{ }^{\circ} \mathrm{C}$ for $24 \mathrm{~h}$, and cultured supernatant $(100 \mu \mathrm{L})$ was mixed with the same volume of Griess reagent $(1 \%$ sulfanilamide, $0.1 \%$ naphthyl ethylenediamine dihydrochloride and 5\% phosphoric acid). After incubation at room temperature for $10 \mathrm{~min}$, the absorbance was measured at $540 \mathrm{~nm}$ with a Micro-Reader (Molecular Devices, Orleans Drive, Sunnyvale, CA, USA). Serum samples from mice were diluted four times with distilled water and deproteinized by adding $1 / 20$ volume of zinc sulfate $(300 \mathrm{~g} / \mathrm{L})$ to a final concentration of $15 \mathrm{~g} / \mathrm{L}$. After centrifugation at $10,000 \times g$ for $5 \mathrm{~min}, 100 \mu \mathrm{L}$ supernatant was applied to a microtiter plate well, followed by adding $100 \mu \mathrm{L}$ of Griess reagent. After $10 \mathrm{~min}$ of color development, the absorbance was measured at $540 \mathrm{~nm}$. Various concentrations of sodium nitrite were used to perform a standard curve.

\subsubsection{Statistical Analysis}

Experimental results were presented as the mean \pm standard deviation (SD) of three parallel measurements. Statistical evaluation was carried out by one-way analysis of variance (ANOVA followed by Scheffe's multiple range tests). Statistical significance is expressed as $* p<0.05,{ }^{* *} p<0.01$ and *** $p<0.001$.

\subsection{Determination of the Anticancer Bioactivity}

\subsubsection{Cell Lines}

Human cancer cell lines, including $\mathrm{T}$ cell leukemia (Jurkat); non-small cell lung carcinoma (NCI-H226), renal carcinoma (A498), lung carcinoma (A549) and fibrosarcoma (HT1080) were obtained from the American Type Culture Collection (Rockville, MD, USA). A nasopharyngeal carcinoma (NPC-TW01) cell line was purchased from Food Industry Research and Development 
Institute (Hsinchu, Taiwan). Tumor cells were maintained in proper medium supplemented with $10 \%$ fetal bovine serum (FBS) at $37{ }^{\circ} \mathrm{C}$ in a humidified atmosphere of $5 \% \mathrm{CO}_{2}$.

\subsubsection{Growth Inhibition Assay}

The evaluation of cell growth and survival was carried out according to Hansen et al. [45] with modification. Briefly, cells were seeded in a 96-well plates and incubated overnight prior to the addition of the designated compounds at various concentrations for three subculture. Two hours before end of treatment, $15 \mu \mathrm{L}$ of MTT solution $(5 \mathrm{mg} / \mathrm{mL})$ was added to each well, and the cells were incubated at $37{ }^{\circ} \mathrm{C}$ for $4 \mathrm{~h}$. Subsequently $75 \mu \mathrm{L}$ lysis buffer (20\% SDS-50\% $N, N$-dimethyl formamide) was added to each well, and the culture plate was incubated at $37{ }^{\circ} \mathrm{C}$ overnight to dissolve the dark blue crystals. The conversion to formazan by metabolically viable cells was measured by absorbance at $570 \mathrm{~nm}$. The percentage of conversion by control cells was used to evaluate the effect of the compounds on cell growth and to determine the $\mathrm{IC}_{50}$ values.

\section{Conclusions}

In summary, forty-four compounds were characterized from the heartwood of Michelia compressa var. formosana. Furthermore, the inhibitory activity on LPS-induced NO production in RAW 264.7 cells and the cytotoxicity on six cancer cells were analyzed. These results provide a potential explanation for the usage of the heartwood of $M$. compressa as the herbal medicine in the treatment of cancer diseases, and they may be potentially useful in developing new anticancer agents.

\section{Acknowledgments}

We thank National Science Council, R.O.C. for financial support of this research.

\section{Conflicts of Interest}

The authors declare no conflict of interest.

\section{References}

1. Keng, H. Magnoliaceae in Flora of Taiwan, 2nd ed.; Editorial Committee of the Flora of Taiwan: Taipei, Taiwan, 1996; pp. 410-414.

2. Hartwell, J.L. Plants used against cancer. A survey. Lloydia 1970, 33, 97-194.

3. Gupta, S.; Mehla, K.; Chauhan, D.; Nair, A. Anti-inflammatory activity of leaves of Michelia champaca investigated on acute inflammation induced rats. Lat. Am. J. Pharm. 2011, 30, 819-822.

4. Liu, C.Y.; Chen, Y.W.; Cheng, M.J.; Lee, S.J.; El-Razek, M.H.A.; Chang, W.H.; Chen, Y.J.; Chen, I.S. Cytotoxic constituents from the root wood of formosan Michelia compressa. J. Chin. Chem. Soc. 2008, 53, 1523-1524.

5. Wang, H.M.; Lo, W.L.; Lu, Y.C.; Yeh, Y.T.; Huang, L.Y.; Huang, J.C.; Chen, C.Y. Chemical constituents from the leaves of Michelia compressa var. formosana. Chem. Nat. Compd. 2009, 45, 931-933. 
6. Wu, C.C.; Wu, C.L.; Huang, S.L.; Chang, H.T. Antifungal activity of liriodenine from Michelia formosana heartwood against wood-rotting fungi. Wood Sci. Technol. 2012, 46, 737-747.

7. Koyama, T.; Morikita, T. Isolation of ceryl alcohol from leaves of Michelia compressa. Chem. Pharm. Bull. 1955, 2, 69-70.

8. Ito, K. Alkaloids of Magnoliaceous plants. XXIV. Alkaloids of Michelia compressa. Yakugaku Zasshi 1960, 80, 705-707.

9. Tomita, M.; Fukukawa, H. Alkaloids of Magnoliaceous plants. XXIII. Alkaloids of Michelia compressa, 3. Alkaloids of the heartwood. Yakugaku Zasshi 1962, 82, 925-927.

10. Yang, T.H. Studies on the alkaloids of Magnoliaceous plants. XXXIII. Alkaloids of Michelia compressa Maxim var. formosana Kanehira. Yakugaku Zasshi 1962, 82, 794-798.

11. Lo, W.L.; Wu, Y.C.; Hsieh, T.J.; Kuo, S.H. Chemical constituents from the stems of Michelia compressa. Chin. Pharm. J. 2004, 56, 69-75.

12. Lo, L.C. Studies on the Constituents of the Parasitic Plants (Aeginetia indica; Cassytha filiformis) and Chinese Medicines (Tetrapanax papyriferus; Michelia compressa) in Taiwan. Ph.D. Thesis, Department of Chemistry, National Tsing Hua University, Taiwan, July 1999.

13. Chen, K.S.; Chang, F.R.; Chia, Y.C.; Wu, T.S.; Wu, Y.C. Chemical constituents of Neolitsea parvigemma and Neolitsea konishii. J. Chin. Chem. Soc. 1998, 45, 103-110.

14. Kawahara, N.; Sekita, S.; Satake, M. Steroids from Calvatia cyathiformis. Phytochemistry 1994, 37, 213-215.

15. Chen, C.Y.; Chang, F.R.; Wu, Y.C. The constituents from the stems of Annona cherimola. J. Chin. Chem. Soc. 1997, 44, 313-320.

16. EI-Feraly, F.S.; Chan, Y.M.; Capiton, G.A. Isolation and characterization of peroxycostunolide (verlotorin) and peroxyparthenolide from Magnolia grandiflora. Carbon-13 nuclear magnetic resonance spectroscopy of costunolide and related compounds. J. Org. Chem. 1979, 44, 3952-3955.

17. Wu, P.L.; Su, G.C.; Wu, T.S. Constituents from the stems of Aristolochia manshuriensis. J. Nat. Prod. 2003, 66, 996-998.

18. Chiang, C.Y.; Leu, Y.L.; Chan, Y.Y.; Wu, T.S. Sodium aristolochates from the flowers and fruits of Aristolochia zollingeriana. J. Chin. Chem. Soc. 1998, 45, 93-97.

19. Wu, T.S.; Leu, Y.L.; Kuoh, C.S.; Jiang, S.D.; Chen, C.F.; Lee, K.H. Cytotoxic principles from Saussurea lappa and Corydalis turtshaninovii f. yanhusuo. J. Chin. Chem. Soc. 1997, 44, 357-359.

20. Guinaudeau, P.H.; Leboeuf, M.; Debray, M.; Cave, A. Alkaloids of Colubrina faralaotra ssp. faralaotra. Planta Med. 1975, 27, 304-318.

21. Lin, F.W.; Damu, A.G.; Wu, T.S. Abietane diterpene alkaloids from Salvia yunnanensis. J. Nat. Prod. 2006, 69, 93-96.

22. Chang, H.M.; Cheng, K.P.; Choang, T.F.; Chow, H.F.; Chui, K.Y. Structure elucidation and total synthesis of new tanshinones isolated from Salvia miltiorrhiza Bunge. J. Org. Chem. 1990, 55, 3537-3543. 
23. Yuuya, S.; Hagiwara, H.; Suzuki, T.; Ando, M.; Yamada, A. Guaianolides as immunomodulators. Synthesis and biological activities of dehydrocostus lactone, mokko lactone, eremanthin, and their derivatives. J. Nat. Prod. 1999, 62, 22-30.

24. Chen, C.Y.; Chang, F.R.; Teng, C.M.; Wu, Y.C. Cheritamine, a new $N$-fatty acyl tryptamine and other constituents from the stems of Annona cherimola. J. Chin. Chem. Soc. 1999, 46, 77-86.

25. Ando, M.; Yoshimura, H. Studies on the syntheses of sesquiterpene lactones. 15. Syntheses of four possible diastereoisomers of Bohlmann's structure of isoepoxyestafiatin. The stereochemical assignment of isoepoxyestafiatin. J. Org. Chem. 1993, 58, 4127-4131.

26. Itokawa, H.; Qiao, Y.; Takeya, K. Anthraquinones, naphthoquinones and naphthohydroquinones from Rubia oncotricha. Phytochemistry 1991, 30, 637-640.

27. Wu, T.S.; Chan, Y.Y.; Leu, Y.L. The constituents of the root and stem of Aristolochia heterophylla Hemsl. Chem. Pharm. Bull. 2000, 48, 357-361.

28. Chang, F.R.; Chen, C.Y.; Hsieh, T.J.; Cho, C.P.; Wu, Y.C. Chemical constituents from Annona glabra III. J. Chin. Chem. Soc. 2000, 47, 913-920.

29. Kikuzaki, H.; Hara, S.; Kawai, Y.; Nakatani, N. Antioxidative phenylpropanoids from berries of Pimenta dioica. Phytochemistry 1999, 52, 1307-1312.

30. Seijas, J.A.; Lera, A.R.; Villaverde, C.; Castedo, L.A. Direct conversion of phenanthrenes to aporphinoids. Heterocycles 1985, 23, 3079-3084.

31. Kuo, P.C.; Kuo, T.H.; Su, C.R.; Liou, M.J.; Wu, T.S. Cytotoxic principles and $\alpha$-pyrone ring-opening derivatives of bufadienolides from Kalanchoe hybrida. Tetrahedron 2008, 64, 3392-3396.

32. Menachery, M.D.; Blake, G.W.; Beiswenger, C.; Freyer, A. Alkaloids from the neutral fraction of Telitoxicum krukovii. Heterocycles 1995, 41, 1425-1430.

33. Jossang, A.; Leboeuf, M.; Cave, A. Synthesis of novel 7,7'-bis-6a,7-dehydronoraporphines. Heterocycles 1987, 26, 2191-2198.

34. Wang, C.C.; Chen, S.S.; Wu, T.S. The facile reversed-phase HPLC resolution of tetrahydrofurofuran nucleus lignans in traditional Chinese medicine: Quantitative analysis of asarinin and sesamin in Asari radix. J. Chin. Chem. Soc. 2003, 50, 261-266.

35. Chou, C.J.; Lin, L.C.; Chen, K.T.; Chen, C.F. Northalifoline, a new isoquinolone alkaloid from the pedicels of Lindera megaphylla. J. Nat. Prod. 1994, 57, 689-694.

36. Ho, J.C.; Chen, C.M.; Row, L.C. Neolignans from the parasitic Plants. Part 2. Cassytha filiformis. J. Chin. Chem. Soc. 2004, 51, 221-224.

37. Luc, P.; Stefaan, V.D.; Mei, G.; Ruoli, B.; Ernest, H.; Arnold, V.; Guy, L. Synthesis and biological evaluation of dihydrobenzofuran lignans and related compounds as potential antitumor agents that inhibit tubulin polymerization. J. Med. Chem. 1999, 42, 5475-5481.

38. Nabeta, K.; Hirata, M.; Ohki, Y.; Samaraweera, S.W.A.; Okuyama, H. Lignans in cell cultures of Picea glehnii. Phytochemistry 1994, 37, 409-413.

39. Xia, Y.M.; You, J.; Wang, Q. Total synthesis of ( \pm )-divanillyltetrahydrofuran ferulate. J. Chem. Sci. 2010, 122, 433-436.

40. Chen, K.S.; Wu, Y.C.; Teng, C.M.; Ko, F.N.; Wu, T.S. Bioactive alkaloids from Illigera luzonensis. J. Nat. Prod. 1997, 60, 645-647. 
41. Zhou, T.S.; Ye, W.C.; Wang, Z.T.; Che, C.T.; Zhou, R.H.; Xu, G.J.; Xu, L.S. $\beta$-Carboline alkaloids from Hypodematium squamuloso-pilosum. Phytochemistry 1998, 49, 1807-1809.

42. Del Río, J.C.; Gutiérrez, A. Chemical composition of abaca (Musa textilis) leaf fibers used for manufacturing of high quality paper pulps. J. Agric. Food Chem. 2006, 54, 4600-4610.

43. Pan, M.H.; Lai, C.S.; Dushenkov, S.; Ho, C.T. Modulation of inflammatory genes by natural dietary bioactive compounds. J. Agric. Food Chem. 2009, 57, 4467-4477.

44. Chang, C.T.; Huang, S.S.; Lin, S.S.; Amagaya, S.; Ho, H.Y.; Hou, W.C.; Shie, P.H.; Wu, J.B.; Huang, G.J. Anti-inflammatory activities of tormentic acid from suspension cells of Eriobotrya japonica ex vivo and in vivo. Food Chem. 2011, 127, 1131-1137.

45. Hansen, M.B.; Nielsen, S.E.; Berg, K. Re-examination and further development of a precise and rapid dye method for measuring cell growth/cell kill. J. Immunol. Methods 1989, 119, 203-210.

(C) 2014 by the authors; licensee MDPI, Basel, Switzerland. This article is an open access article distributed under the terms and conditions of the Creative Commons Attribution license (http://creativecommons.org/licenses/by/3.0/). 